\title{
Magnesium sulphate: A Life Saving Drug
}

\author{
Thapa K,' Jha R² \\ 'Paropakar Maternity and Women's Hospital, Thapathali, ${ }^{2}$ Tribhuvan University Teaching Hospital, Maharajguni, \\ Kathmandu, Nepal
}

\section{ABSTRACT}

A retrospective study of 68 eclamptic women who received Magnesium sulphate at Koshi Zonal Hospital were analyzed during a one year period (2006-2007 AD). Maternal conditions at admission, associated complications in mothers and babies, delivery outcomes and cause of death were also studied in each case.

There were 5240 deliveries during the period of analysis. Of which 4976 were live births, pregnancy induced hypertension was $0.89 \%(47), 0.74 \%$ (39) presented with pre-eclampsia, 0.30 (16) cases with severe pre-eclampsia and 0.43 (23) cases with mild pre-eclampsia. During this period 1.3\% (68) of eclampsia presented to the hospital. Of which $67.7 \%$ presented with ante-partum eclampsia, $22.1 \%$ with intrapartum eclampsia and $10.3 \%$ with post partum eclampsia. Majority of women $(63.2 \%)$ were between 20-25 years of age, while teenage pregnancy contributed $30.88 \%$ of eclamptic cases. The diastolic blood pressure was $>110 \mathrm{~mm}$ of $\mathrm{Hg}$ in $45.6 \%$ of cases, $90-110 \mathrm{mmHg}$ in $50 \%$ of cases and in $4.4 \%$ the it was $<90 \mathrm{mmHg}$. $94.1 \%$ presented to the hospital in an unconscious state, $79.4 \%$ of eclamptic women received the full dose of magnesium sulphate (initial loading plus maintenance dose), while rest failed to receive the full dose. Nine women with severe pre-eclampsia received magnesium sulphate as a prophylactic measure. $17.7 \%$ women had home delivery, one patient left against medical advice and one was referred to a tertiary care center. Caesarian Section (Lower Segment) was performed in $35.2 \%$ of cases, $30.8 \%$ had normal vaginal deliveries and $5.8 \%$ had pre term delivery. About $69.6 \%$ babies were born alive, $8.7 \%$ were still births, $11.6 \%$ were neonatal deaths and $4.4 \%$ of babies had to be admitted to the neonatal intensive care. Eclamptic women stayed less than one week in the hospital in majority of cases (64.7\%), between 1-2 weeks in 32.4\% and more than two weeks in $2.9 \%$. Maternal complications included decreased urinary output, pulmonary edema in three cases; chest and wound infection two cases each; post partum psychosis, vulval haematoma, severe headache one case each. There were seven maternal deaths during this period and eclampsia contributed to one of the deaths.

Eclampsia is a major cause of maternal and perinatal morbidity and mortality in our setup. Magnesium sulphate is an excellent drug of choice in management of eclampsia and pre-eclampsia. Wider coverage of pre-natal care, timely referral and optimal management of cases of eclampsia with magnesium sulphate in hospitals are key issues to prevent mortality/morbidity associated with it.

Key words: eclampsia, pre-eclampsia, magnesium sulphate, maternal morbidity, moratlity

Correspondence:
Dr. Kusum Thapa
Paropakar Maternity and Women's Hospital
Thapathali, Kathmandu, Nepal
Phone: +977-9841555740
Email: kusumthapa2006@hotmail.com


Thapa et al. Magnesium sulphate: A Life Saving Drug

\section{INTRODUCTION}

Maternal health is a crucial part of the health care delivery system of any nation, with special focus on reducing the morbidity as well as mortality of the complications related to pregnancy. Prenatal care that a woman receives during pregnancy, labor and in the postpartum period is vital for the survival of both the mother as well as the baby. Currently, lots of women in Nepal die during pregnancy, labor and in the postpartum period due to preventable causes such as eclampsia, hemorrhage and abortion related complication. Eclamptic and non-eclamptic hypertensive disorders of pregnancy are responsible for a high number of maternal and perinatal morbidity and mortality in Nepal. Majority of these cases could have been detected during the pre natal period and timely intervention can save millions of lives. However there is a wide disparity between urban women seeking prenatal care and rural women seeking prenatal care $52 \%$ vs $26 \%$ of women. The real challenge is to tap this rural population much earlier in order to improve maternal as well as neonatal health.

Magnesium sulfate $\left(\mathrm{MgSO}_{4}\right)$ is the agent most commonly used for treatment of eclampsia and prophylaxis of eclampsia in patients with severe pre-eclampsia. ${ }^{1}$ Koshi Zonal Hospital has been training service provider in basic emergency obstetrical care, midwifery refresher training since 2002 AD. Till date 173 health care workers have been trained at the hospital. Refocused antenatal care, use of magnesium sulphate $\left(\mathrm{MgSo}_{4}\right)$ have been instrumental in improving the lives of women in the region. This study analyzes the outcome of using magnesium sulphate for eclampsia over a year's period.

\section{MATERIAL AND METHODS}

This is a retrospective study conducted in the Koshi Zonal Hospital during July 17, 2006 to July 16, 2007. After the institutional approval data were collected in which sixty eight women with ecalmapsia, who received magnesium sulphate were included in this study. Maternal conditions at admission, diastolic blood pressure (BP), mode of delivery and fetal outcomes, complications in both mother and neonate, duration of admission and causes of maternal deaths were analyzed.

Statistical analysis were done by using statistical package for social science (SPSS) version 13 for windows.

\section{RESULTS}

There were 5240 deliveries at Koshi Zonal Hospital during one year study period. Of which 4976 were live births. During this one year period $1.3 \%,(68)$ women presented with eclampsia $(1.3 \%), 0.74 \%$ (39) with pre-eclampsia, $0.30 \%$ (16) with severe pre-eclmapsia, $0.43 \%$ (23) with mild pre eclampsia and $0.89 \%$ (47) with pregnancy induced hypertension. Majority of women presented to the emergency in an unconscious state $(94.1 \%)$. Ante partum eclampsia was seen in $67.7 \%$ of cases, intra partum in $22.1 \%$ and post partum eclampsia in $10 \%$. In $45.6 \%$ of the cases the BP on admission was $>110 \mathrm{mmHg}, 50 \%$ had $\mathrm{BP}$ ranging from $90-110 \mathrm{mmHg}$ and in $4.4 \%$ the BP was below 90 $\mathrm{mmHg}$. Urine albumin was tested on admission for all eclamptic women, $20.6 \%$ did not have the presence of albumin on admission.

Majority of the women were between the ages of 20-25 years age group $63.24 \%$, adolescent mothers comprised $30.88 \%$ (Table 1 ). As far as the parity was concerned most of them were primi gravidas, seen in $85.29 \%$ of cases. However maximum number of women had eclampsia at term with $67.65 \%$ of cases and only $8.82 \%$ had post dated pregnancy.

Table 1. Age wise distribution

\begin{tabular}{ccc}
\hline Age & Number & Percentage \\
\hline$\leq 19$ & 21 & 30.88 \\
$20-25$ & 43 & 63.24 \\
$26-30$ & 2 & 2.94 \\
$31-35$ & 2 & 2.94 \\
$>35$ & 0 & 0.00 \\
\hline
\end{tabular}

Table 2. Parity of the patients

\begin{tabular}{lcc}
\hline Parity & Number & Percentage \\
\hline Primi & 58 & 85.29 \\
Multi & 10 & 14.71 \\
\hline
\end{tabular}

Table 3. Period of Gestation

\begin{tabular}{lcc}
\hline Period of Gestation & Number & Percentage \\
\hline Term & 46 & 67.65 \\
Preterm & 16 & 23.53 \\
Post term & 6 & 8.82 \\
\hline
\end{tabular}

Significant number of eclampsia patients presented to the emergency in an unconscious state $(94.1 \%)$. Ante partum eclampsia was seen in $67.7 \%$ of cases, intra partum in $22.1 \%$ and post partum eclampsia in $10 \%$. In $45.6 \%$ of the cases the BP on admission was $>110$ $\mathrm{mmHg}, 50 \%$ had BP ranging from $90-110 \mathrm{mmHg}$ and in $4.4 \%$ the BP was below $90 \mathrm{mmHg}$. Urine albumin was tested on admission for all eclamptic women, $20.6 \%$ did not have the presence of albumin on admission.

All women received Pitchart's regime of magnesium sulphate, $79.4 \%$ received full dose (loading dose 
Thapa et al. Magnesium sulphate: A Life Saving Drug

intravenous) and maintenance dose till 24 hours after delivery. In the rest of the eclampsia patients, magnesium sulphate had to be discontinue due to variety of reasons, (Table 4 ), decreased urinary output being the main reason. There were no cases of magnesium sulphate toxicity. In one patient immediately after giving the loading dose of magnesium sulphate, she developed eclamptic fits. Magnesium sulphate was given in nine cases as a prophylactic measure. $17.7 \%$ of women had a home delivery.

Table 4. Dose of Magnesium Sulphate

\begin{tabular}{lccl}
\hline Dose of MgSo4 & No. & $\%$ & $\begin{array}{l}\text { Reason for } \\
\text { discontinuation }\end{array}$ \\
\hline Full dose & 54 & 79.41 &
\end{tabular}

\begin{tabular}{lcrl}
$\begin{array}{l}\text { Loading Dose } \\
\text { only }\end{array}$ & 3 & 4.41 & $\begin{array}{l}\text { Decreased urinary } \\
\text { output }\end{array}$ \\
$\begin{array}{l}\text { Loading }+1 \\
\text { Maintainance }\end{array}$ & 2 & 2.94 & $\begin{array}{l}\text { Decreased urinary } \\
\text { output }\end{array}$ \\
$\begin{array}{l}\text { Loading }+2 \\
\text { Maintainance }\end{array}$ & 4 & 5.88 & $\begin{array}{l}\text { Decreased urinary } \\
\text { output }\end{array}$ \\
\hline $\begin{array}{l}\text { Loading }+3 \\
\text { Maintainance }\end{array}$ & 1 & 1.47 & $\begin{array}{l}\text { Decreased urinary } \\
\text { output }\end{array}$ \\
$\begin{array}{l}\text { Loading }+4 \\
\text { Maintainance }\end{array}$ & 4 & 5.88 & $\begin{array}{l}\text { Decreased urinary } \\
\text { output + Loss of P } \\
\text { reflex }\end{array}$ \\
\hline
\end{tabular}

*Only one women developed fit after starting MgSO4. This was immediately after the intravenous (IV) loading dose.

Table 5. Dose of MgSO4 in Severe Pre-eclampsia

\begin{tabular}{lccl}
\hline Dose & No. & $\%$ & $\begin{array}{l}\text { Reason for } \\
\text { discontinuation }\end{array}$ \\
\hline Full & 7 & 77.78 & \\
$\begin{array}{l}\text { Loading }+1 \\
\text { Maintainance }\end{array}$ & 1 & 11.11 & $\begin{array}{l}\text { Decreased urinary } \\
\text { output } \\
\text { Loading }+4\end{array}$ \\
$\begin{array}{l}\text { Maintainance } \\
\text { Refused to take } \\
\text { further dose }\end{array}$ \\
\hline
\end{tabular}

Eclampsia case who presented in early stage of labor had an emergency Lower Segment Caesarian Section (LSCS) in $35.29 \%$ of cases, followed by vaginal delivery in 30.88 cases (Table 6). The instrumental delivery rate was negligible $2.94 \%$. One case of antepartum eclampsia left against medical advice despite the couselling of consequences. Another case was referred to tertiary care center for better neonatal intensive care facilities on patient's demand.
Table 6. Mode of Delivery

\begin{tabular}{lcc}
\hline Mode of Delivery & Number & Percentage \\
\hline LSCS & 24 & 35.29 \\
Forceps & 2 & 2.94 \\
Normal delivery & 21 & 30.88 \\
PVD & 4 & 5.88 \\
Vaginal delivery SB & 3 & 4.41 \\
Home delivery & 12 & 17.65 \\
Referred to BPKIHS & 1 & 1.47 \\
LAMA & 1 & 1.47 \\
\hline
\end{tabular}

There were several maternal complications that occurred while in the hospital, post partum psychosis, severe headache and vulval hematoma one case each. Chest and wound infection was seen in two cases, and pulmonary edema in three cases which was timely recognized and treated appropriately. There were seven maternal deaths during the study period. The mortality was due to post partum hemorrhage in two cases, anemia, septic abortion, ruptured uterus, puerperal sepsis and eclampsia were responsible one case each for maternal mortality.

There was one maternal death due to eclampsia during the study period, despite all emergency measures. The case was a 21 year primi admitted with a history of multiple fits at home. She was unconscious with a blood pressure of $150 / 110 \mathrm{mmHg}$, urinary albumin absent but there was evidence of pulmonary edema. She was immediately given diuretics and broad spectrum antibiotics. The urinary output was adequate. Bed side clotting test was normal. Loading dose of MgSO4 was given. Despite all these measures, she collapses one later of her presentation.

Birth weight is a good indicator for the survival of the baby. The majority of women delivered babies more than $2.5 \mathrm{~kg}$ in $40.48 \%$ cases, low birth weight was seen in $41.9 \%$ of cases. Several neonatal deaths occurred mainly due to asphyxia in $11.59 \%$ of cases while neonatal death was seen in $4.35 \%$.

\section{DISCUSSION}

Maternal mortality ratio in Nepal has dramatically declined to 280 per 100,000 live births, despite the political instability and decade long insurgency. Some of the factors that have contributed to this decline are increased awareness, expansion of health facilities, immunization and antenatal care. Contraceptive prevalence rate also has increased from $39 \%$ to $48 \%$ in the last five years. The average family size has declined from 4.6 children in 1996, to 4.1 in 2001 and 3.1 in 2006. ${ }^{2}$ Abortion also has been legalized since 2004. Since less women are pregnant, there are less maternal 
Thapa et al. Magnesium sulphate: A Life Saving Drug

Table 7. Cost of Medicines for Eclampsia Patients

\begin{tabular}{|c|c|c|c|}
\hline Drugs & Quantity & Unit cost & Total \\
\hline IV Cannula & 1 & Rs. 65.00 & Rs. 65.00 \\
\hline IV Set & 1 & Rs. 50.00 & Rs. 50.00 \\
\hline Inj Ringer Lactate & 2 & Rs. 37.00 & Rs.74.00 \\
\hline Foleys Catheter & 1 & Rs. 75.00 & Rs. 75.00 \\
\hline Urobag & 1 & Rs.50.00 & Rs. 50.00 \\
\hline Inj MgSO4 & 40 ampules & Rs.7.00 & Rs. 280.00 \\
\hline Inj Calcium Gluconate 10\% & 1 ampule & Rs. 20.00 & Rs 20.00 \\
\hline Inj. 2\% Lignocaine & 1 vial & Rs. 35.00 & Rs. 35.00 \\
\hline Disposable syringe $20 \mathrm{cc}$ & 2 & Rs. 14.00 & Rs. 50.00 \\
\hline Disposable Syringe 10cc & 8 & Rs. 15.00 & Rs. 120.00 \\
\hline Disposable Syringe 5cc & 1 & Rs 3.00 & Rs.3.00 \\
\hline Water for injection & 3 ampules & Rs 1.00 & Rs. 3.00 \\
\hline Cap Nefidipine & 10 capsule & Rs 1.15 & Rs. 11.50 \\
\hline TOTAL & & & Rs $836.00(\$ 13)$ \\
\hline
\end{tabular}

Table 8. Fetal Outcome

\begin{tabular}{lcc}
\hline Weight & No. & $\%$ \\
\hline$>2.5 \mathrm{~kg}$ & 28 & 40.58 \\
$1.5-2.5$ & 24 & 34.78 \\
$<1.5$ & 5 & 7.25 \\
Weight (Wt) not known(Home & 12 & 17.39 \\
Delivery, LAMA, Mother & & \\
Expired, In utero transfer) & & \\
\hline
\end{tabular}

Table 9. Baby Outcome

\begin{tabular}{llc}
\hline Baby Outcome & No. & $\%$ \\
\hline Live born & 48 & 69.56 \\
SB & 6 & 8.69 \\
NND & 8 & 11.59 \\
NICU & 3 & 4.35 \\
Refered/LAMA/Mother expired & 3 & 4.35 \\
\hline
\end{tabular}

deaths are noted. But at a closer look at the department of health services (DHS) data, there is a wide disparity between urban and rural population. About $85 \%$ of women in urban areas receive antenatal checkup (ANC) from a skilled birth attendant, while only $38 \%$ of rural population. Data regarding delivery in a health facility is also alarming, $38 \%$ of children in urban areas are born at a health facility, compared to only $14 \%$ of the rural population. ${ }^{2}$ In our study $17.65 \%$ women delivered at home and presented to the emergency department of Koshi Zonal Hospital with post partum eclampsia. If we see national figure also less than one fifth of births take place with the assistance of skilled birth attendant. The challenge lies in meeting the health demands of the rural population and increasing the awareness for delivery by a skilled birth attendant. Earlier studies have shown eclampsia as one of the leading causes of death, in the eastern region of the country. ${ }^{3}$

The incidence of eclampsia is high in countries of South East Asia and Africa have a higher incidence as compared to the incidence in the West. ${ }^{4-9}$

The incidence of eclampsia at Koshi Zonal Hospital was $1.3 \%$ similar to the incidence seen in Nigeria. However the population here are maximum in the age group of $20-25$ in $83.3 \%$ cases and adolescent group was $30.88 \%$ unlike the $16.5 \%$ of eclampsia patients in Ethiopian study. Majority of our women were primi gravidas 83.3\%, other studies in India, Turkey, Ethiopia also have quoted a similar age/parity profile.

The mortality here was very low (only one death) in contrast to the high number of maternal deaths due to eclampsia seen in Ethiopia or India in which $28 \%$ and $24 \%$ women died due to eclampsia. Another factor responsible for this could be that many women who had eclampsia never made it to the hospital, thus we may not have statistics to highlight the magnitude of the problem. Though there are not statistics of previous years of maternal mortality ratio figures from the hospital, it is not difficult to conclude that magnesium sulphate has been instrumental in improving patients of eclampsia. We can however conclude that since not a single case of magnesium toxicity occurred during the study period, all eclampsia patients were treated well. Previously diazepam and phenytoin were also used. Retrospective studies in Thailand and Tureky have also demonstrated magnesium sulphate as an excellent drug for the management of eclampsia/pre-eclampsia 
Thapa et al. Magnesium sulphate: A Life Saving Drug

and reduction of maternal mortality. The data from this region has shown that there is a significant decline of maternal deaths with the use of magnesium sulphate, from $16 \%$ to $8 \%$ at Dhaka Medical College. Similar results have also been seen at postgraduate institute Chandigarh, Turkey, Cambodia, as well as in Bangkok, Thailand. ${ }^{10-18}$

Lancet in 2001 published a international multi-center randomized trial comparing standard anticonvulsant regimes were compared, which involved 1687 women with eclampsia. The risk of recurrent convulsions were less in magnesium sulphate group as compared to phenytoin or diazepam and there is now compelling evidence in favor of magnesium sulphate, than other drugs for the treatment of eclampsia except for one case who had repeated convulsions soon after the loading dose of magnesium sulphate. Here in this study there are not see many cases of postpartum eclampsia at our hospital, unlike the Ethopian study, $10 \%$ vs $15.7 \% .^{9}$

Several studies have concluded that high perinatal mortality/morbidity is associated with babies born to eclampsic mothers. In our study also we had $11.6 \%$ neonatal deaths. Unlike the Cambodian study of $20 \%$ still birth our still birth rate was much lower $8.7 \%$. The neonatal admission rate was $4.4 \%$. Studies in Thailand and India have quoted a high cesarean section rate, associated with better peri-natal outcome. Even though our operative rate was not that high $35.29 \%$ compared to $57 \%$ in Thailand, or $79 \%$ in Nova Scotia, the perinatal outcomes are not as bad in comparison to the two. ${ }^{12}$

The limitation of this study was the study was based on the data available in the medical record section. To prove the efficacy and safety of $\mathrm{MgSO}_{4}$ we need to have a more larger population study.

\section{CONCLUSION}

It has been well established that eclampsia is a major cause for both maternal and perinatal mobidity and mortality. Till there are emergency obstetrical care services available throughout the country, advocacy for institutional delivery, early recognition/ referral of hypertensive disorders of pregnancy, timely management of pre-eclampsia/eclampsia, use of magnesium sulphate are key strategies to help improve the maternal mortality/morbidity of mothers and babies in Nepal.

\section{REFERENCES}

1. Lu JF, Nightingale $\mathrm{CH}$. Magnesium sulfate in eclampsia and pre-eclampsia: pharmacokinetic principles. Clin Pharmacokinet 2000 Apr;38(4):305-14.

2. Ministry of Health and Population (MOHP) [Nepal], New ERA, and Marcro International Inc. 2007.

3. Goswami A, Kasliwal M R, Lekraj H G, Urala M S. Maternal mortality in a Tertiary care centre in Nepal. Trop J Obstet Gynaecol 2004; 21:168-171.

4. Begum R, Begum A, Bullough CH, Johanson RB. Reducing maternal mortality from eclampsia, using magnesium sulphate. Eur J Obstet Gynecol Reprod Biol 2000 Oct;92(2):2234.

5. Sawhney H, Aggarwal N, Biswas R, Vasishta K, Gopalan S. Maternal mortality associated with eclampsia and severe preeclampsia of pregnancy. J Obstet Gynaecol Res 2000 Oct;26(5):351-6.

6. Which anticonvulsant for women with eclampsia? Evidence from the Collaborative Eclampsia Trial. Lancet. 2001 Jan 27;357(9252):312.

7. Witlin AG, Sibai BM Magnesium sulfate therapy in preeclampsia and eclampsia. Obstet Gynecol 1998 Nov;92(5):883-9.

8. Azria E, Tsatsaris V, Goffinet F, Kayem G, Mignon A, Cabrol D. Magnesium sulfate in obstetrics: current data. J Gynecol Obstet Biol Reprod (Paris) 2004 Oct;33(6 Pt 1):510-7.

9. Gessessew A. Maternal complications--in a zonal hospital. Ethiop Med J 2007 Jan;45(1):47-54.

10. Chhabra S, Kakani A Maternal mortality due to eclamptic and non-eclamptic hypertensive disorders: a challenge. J Obstet Gynaecol 2007 Jan;27(1):25-9.

11. Onuh SO, Aisien AO Maternal and fetal outcome in eclamptic patients in Benin City, Nigeria. J Obstet Gynaecol 2004 Oct;24(7):765-8.

12. Lee $\mathrm{W}, \mathrm{O}^{\prime}$ Connell CM, Baskett TF. Maternal and perinatal outcomes of eclampsia: Nova Scotia, 1981-2000. J Obstet Gynaecol Can 2004 Feb;26(2):119-23.

13. Chinayon P. Clinical management and outcome of eclampsia at Rajavithi Hospital. J Med Assoc Thai 1998 Aug;81(8):57985.

14. Swain S, Ojha KN, Prakash A, Bhatia BD. Maternal and perinatal mortality due to eclampsia. Indian Pediatr 1993 Jun;30(6):771-3.

15. Abate M, Lakew Z. Eclampsia a 5 years retrospective review of 216 cases managed in two teaching hospitals in Addis Ababa. Ethiop Med J 2006 Jan;44(1):27-31.

16. Taner CE, Hakverdi AU, Aban M, Erden AC, Ozelbaykal U Prevalence, management and outcome in eclampsia. Int J Gynaecol Obstet 1996 Apr;53(1):11-5.

17. Koum K, Hy S, Tiv S, Sieng T, Obara H, Matsui M, Fujita N. Characteristics of antepartum and intrapartum eclampsia in the National Maternal and Child Health Center in Cambodia. J Obstet Gynaecol Res 2004 Apr;30(2):74-9.

18. Obed SA, Wilson JB, Elkins TE. Eclampsia: 134 consecutive cases. Int J Gynaecol Obstet 1994 May;45(2):97-103. 